\title{
Estrogen receptor $\alpha$ polymorphisms and postmenopausal breast cancer risk
}

\author{
A. M. González-Zuloeta Ladd $\cdot$ A. Arias Vásquez $\cdot$ F. Rivadeneira • \\ C. Siemes · A. Hofman - B. H. Ch. Stricker · H. A. P. Pols · A. G. Uitterlinden · \\ C. M. van Duijn
}

Received: 6 March 2007 / Accepted: 7 March 2007/Published online: 24 April 2007

(C) Springer Science+Business Media B.V. 2007

\begin{abstract}
Background The estrogen receptor alpha (ESR1) is a mediator of estrogen response in the breast. The most studied variants in this gene are the PvuII and XbaI polymorphisms, which have been associated to lower sensitivity to estrogen. We evaluated whether these polymorphisms were associated with breast cancer risk by means of an association study in a population of Caucasian postmenopausal women from the Rotterdam study and a meta-analysis of published data.

Methods The PvuII and XbaI polymorphisms were genotyped in 3,893 women participants of the Rotterdam Study. Baseline information was obtained through a questionnaire. We conducted logistic regression analyses to assess the risk of breast cancer by each of the ESR1 genotypes. Meta-analyses of all publications on these relations were done by retrieving literature from Pubmed and by further checking the reference lists of the articles obtained.

Results There were 38 women with previously diagnosed breast cancer. During follow-up, 152 were additionally diagnosed. The logistic regression analyses showed no difference in risk for postmenopausal breast cancer in
\end{abstract}

A. M. González-Zuloeta Ladd · A. A. Vásquez .

C. Siemes · A. Hofman - B. H. Ch.Stricker ·

A. G. Uitterlinden · C. M. van Duijn ( $₫)$

Department of Epidemiology \& Biostatistics,

Erasmus MC, P.O. Box 2040,

Rotterdam 3000 CA, The Netherlands

e-mail: c.vanduijn@erasmusmc.nl

F. Rivadeneira - C. Siemes - H. A. P. Pols ·

A. G. Uitterlinden

Department of Internal Medicine, Erasmus MC,

Rotterdam, The Netherlands carriers of the PvuII or XbaI genotypes neither in overall, incident or prevalent cases. No further evidence of a role of these variants was found in the meta-analysis.

Conclusions Our results suggest that the ESR1 polymorphisms do not play a role in breast cancer risk in Caucasian postmenopausal women.

Keywords Estrogen receptor - Polymorphism · Breast cancer

\section{Introduction}

Family history is one of the strongest risk factors for breast cancer [1]. It has been shown that the heritability of this disease is $\sim 30 \%$ [2]. The most important determinants of risk for breast cancer are related to endogenous hormone levels and major reproductive events [3], thus, suggesting that genes in the estrogen pathway may influence breast cancer risk.

The estrogen receptor alpha (ESR1) is one of the most important mediators of hormonal response in estrogensensitive tissues such as the breast [4] and plays a crucial role in breast growth and differentiation as well as in the development of cancer [5]. The human ESR1 gene is localized on chromosome 6q24-q27 [6], it extends more than $140 \mathrm{~kb}$ and includes eight exons [7]. The most studied variants in this gene are the PvuII $(\mathrm{C} / \mathrm{T})$ and $\mathrm{XbaI}(\mathrm{G} / \mathrm{A})$ polymorphisms in intron 1, 397 and $351 \mathrm{bp}$ upstream of exon 2 respectively [8,9]. These variants have been implicated in gene expression by influencing transcription [10]. While some studies have found an increased risk for the A and T alleles of the XbaI and PvuII polymorphisms [4, $9,10]$, others have found an increased risk only for the $X$ (G) allele of XbaI [11, 12]. In addition, other studies found 
no effect at all for either of these polymorphisms [4, 13]. These alleles were correlated with high bone mineral density and height in other studies, including one performed in our study population, [14, 15], suggesting a stronger estrogenic effect in $\mathrm{P}(\mathrm{C})$ and $\mathrm{X}(\mathrm{G})$ allele carriers [14].

The aim of our study was to evaluate the effect of these polymorphisms on breast cancer risk by performing an association analysis in a population based study of Caucasian postmenopausal women. Further, we performed meta-analyses of all available published data on these polymorphisms and the risk of breast cancer.

\section{Materials and methods}

Study population and measurements

Our study population is part of the Rotterdam study [16]. Inhabitants of the suburb of Ommoord aged 55 or older were invited to participate and 7983 agreed to do so (response rate $78.1 \%$ ). Study participants signed an informed consent and the Medical Ethics Committee of the Erasmus Medical Center approved the study. Our study group was composed of 4,878 postmenopausal women. Information on risk factors such as age at entry, age at menarche, age at menopause, parity, body mass index (BMI), waist hip ratio (WHR) and hormone replacement therapy use (HRT) was retrieved at baseline through a questionnaire. BMI was calculated by dividing the weight in kilograms by the height (in meters) squared [17].

\section{Case identification and validation}

Three different databases were used for patient identification. First, cases diagnosed by general practitioners in the research area (Ommoord) were collected (International Classification of Primary Care (code X76)). Second, the Dutch National Registry of all hospital admissions (LMR) was consulted to detect all malignancy related hospital admissions for study participants. Finally, regional pathology databases were linked to the Rotterdam Study to identify patients. Subsequently, breast cancer cases were validated by a physician on the basis of medical records of the general practitioner, discharge letters and pathology reports. Only pathologically confirmed cases were considered in the analysis. The index date was defined as the earliest date found in the pathology report.

Genotyping \& data analysis

Out of the 4,878 women participating in our study, 3,893 (80\%) were successfully genotyped for the PvuII and XbaI polymorphisms. The genotyping procedures have been described previously [14]. Loss to follow up was assessed to verify it was independent of genotype. Categorical variables, such as parity and HRT, were compared between genotype groups using the chi-squared test. Continuous variables, (age at entry, age at menopause, BMI and WHR) were compared using the independent sample MannWhitney test. We used logistic regression to study the risk of breast cancer by ESR1 genotype. This analysis was performed using SPSS version 11, since there is no clear risk allele from the literature, we took the TT (PvuII) and $\mathrm{AA}(\mathrm{XbaI})$ genotypes as reference because they have been associated to lower sensitivity to estrogen in our population [14]. We also performed a trend test to evaluate if the number of risk alleles carried had an effect on disease risk. Hardy-Weinberg equilibrium (HWE) was assessed for both polymorphisms using Markov-Chain Monte-Carlo approximation of the exact test implemented in the GENEPOP package V 3.3 [18].

Meta-analysis

We searched PubMed until October 2006 for all casecontrol studies on the association of the PvuII and XbaI polymorphisms in the ESR1 gene and breast cancer. Our search strategy was based on the keyword "breast cancer", combined with "estrogen receptor" and "polymorphism". To verify that all studies were retrieved, the reference lists of all publications were searched for additional studies. We excluded studies from our analyses if the genotype frequencies in the control population were out of HardyWeinberg or if their data had been previously used in another study. To quantify the strength of association, pooled odds ratios (ORs) and 95\% confidence intervals (CI) were calculated using the random-effects model of the DerSimonian and Laird method [19]. The degree of heterogeneity between the study results was tested by the inconsistency statistic $\left(I^{2}\right)$. Funnel plots were used to evaluate publication bias [20]. Data were analysed using Review Manager, version 4.2 (Cochrane Collaboration, Oxford, UK).

\section{Results}

The total loss of follow-up for the genotyped participants was $8.4 \%$ and it was not dependent on ESR1 genotype $(P=0.51)$. The genotype frequencies of both polymorphisms were in HWE proportions $\left(X^{2} P=0.33\right.$ for $P v u I I$ and $X^{2} P=0.31$ for $\left.X b a I\right)$. In Table 1 we show the baseline characteristics of our study population. We found that all cases (incident and prevalent) were significantly younger at 
Table 1 General characteristics of the study population

\begin{tabular}{llll}
\hline & Cases & Controls & Total \\
\hline Total studied (\%) & $190(4.7 \%)$ & $3513(95.3)$ & 3703 \\
Mean age of entry (SD)* & $67.80(7.7)$ & $70.36(9.6)$ & $70.24(9.6)$ \\
Mean age at death (SD)* & $77.30(8.6)$ & $84.46(8.7)$ & $84.12(8.8)$ \\
Mean age at menarche (SD) & $13.57(1.7)$ & $13.68(1.8)$ & $13.67(1.8)$ \\
Mean age at menopause (SD)* & $49.51(4.8)$ & $52.19(13.6)$ & $52.07(13.3)$ \\
Mean number of children (SD)* & $1.77(1.6)$ & $2.12(1.7)$ & $2.10(1.7)$ \\
Parity (SD) ( $\geq 1$ child)* & $121(71.6)$ & $2640(79.4)$ & $2761(79)$ \\
Hormone replacement therapy(\%) & $27(21.1)$ & $504(19.5)$ & $531(19.6)$ \\
Mean BMI (SD) & $27.10(3.9)$ & $26.67(4.1)$ & $26.69(4.1)$ \\
Mean WHR (SD) & $0.87(.09)$ & $0.87(.09)$ & $0.87(.09)$ \\
\hline
\end{tabular}

$* P$-value $<0.05$

entry than controls $(P<0.001)$ and also died earlier during follow-up $(P<0.001)$, when using incident cases only we found the same significant differences ( $P$ for age at entry $<0.0001, P$ for age at death $<0.0001)$. We also found that cases had significantly fewer children than controls $(P=0.04)$. We did not find any significant differences in these baseline characteristics between genotype groups (data not shown).

There were 38 women with previously diagnosed postmenopausal breast cancer who entered the study. During follow-up, 152 were additionally diagnosed. There were no significant differences in the number of cases between the PvuII ( $P=0.43$ for overall cases) and XbaI genotypes ( $P=0.33$ for overall cases).

We carried out a logistic regression analysis adjusting for age at entry, age at menopause, BMI, WHR and HRT for both polymorphisms separately (Table 2). Since the T and $\mathrm{A}$ alleles of these polymorphisms have been correlated to lower estrogenic effects, we used the TT and AA genotypes as our reference categories in the analyses. There were no significant differences in risk for breast cancer among carriers of the different genotypes of the $P v u I I$ or XbaI polymorphisms in the ESR1 gene. There was a non-significant tendency of the $\mathrm{C}$ allele of $P$ vuII ( $P$-for trend $=0.22)$ and $\mathrm{G}$ allele of the $\mathrm{XbaI}(P$-for trend 0.26$)$ to be over represented in patients.

Table 2 Odds ratios for breast cancer risk for PvuII and XbaI genotypes

\begin{tabular}{|c|c|c|c|}
\hline & Overall & Incident & Prevalent \\
\hline \multicolumn{4}{|c|}{ PvuII } \\
\hline $\mathrm{TT}$ & Ref & Ref & Ref \\
\hline $\mathrm{TC}$ & $0.9(0.6-1.4)$ & $1.0(0.6-1.6)$ & $0.8(0.3-2.1)$ \\
\hline $\mathrm{CC}$ & $1.4(0.8-2.2)$ & $1.4(0.8-2.5)$ & $1.2(0.4-3.3)$ \\
\hline \multicolumn{4}{|c|}{ XbaI } \\
\hline AA & Ref & Ref & Ref \\
\hline GA & $1.2(0.8-1.7)$ & $1.3(0.8-2.0)$ & $0.8(0.4-1.9)$ \\
\hline GG & $1.3(0.7-2.2)$ & $1.5(0.8-2.8)$ & $0.5(0.2-2.4)$ \\
\hline
\end{tabular}

To evaluate our data together with those in the literature we performed meta-analyses. We identified nine articles studying the relation between XbaI and PvuII polymorphisms and the risk of breast cancer [4, 9-12, 21-24]. We excluded from our analyses one study [11], since the data was used in another study [4]. Furthermore, two studies were excluded since genotype frequencies of controls were out of HWE proportions [9, 10]. Using the random effects model we did not find any difference in risk among XbaI and PvuII genotypes (Figs. 1 and 2). High inter-study heterogeneity can render the interpretation of the results of a meta-analysis difficult and although we found high heterogeneity in the G/A versus GG comparison there was no significant heterogeneity in the other three comparisons. Additionally, the evaluation of the funnel plots did not suggest evidence for publication bias.

\section{Discussion}

We performed an association study to evaluate the relationship of two well-studied polymorphisms in the ESR1 gene and the risk of breast cancer in Caucasian postmenopausal women from the Rotterdam Study. Using logistic regression analysis, we found no evidence of effect, with only a non-significant increase in breast cancer risk for AA carriers of the XbaI polymorphism (overall OR $=1.3,95 \%$ $\mathrm{CI}=0.7-2.2)$ and for TT carriers of the PvuII variant (overall $\mathrm{OR}=1.4,95 \% \mathrm{CI}=0.8-2.2$ ). Additionally we performed meta-analyses of published data to examine the effect of both polymorphisms. These meta-analyses also suggest there are no differences in risk among genotype groups of these two ESR1 variants.

The XbaI and PvuII polymorphisms are situated in intron 1 and their functionality has not yet been demonstrated. Moreover, it has been suggested their effects could be the result of high linkage disequilibrium with functional variants that affect sensitivity to estrogen [13].

One of the limitations of our study is the limited number of breast cancer cases present in our population. Never- 
Fig. 1 Meta-Analyses ESR1 XbaI polymorphism and breast cancer risk

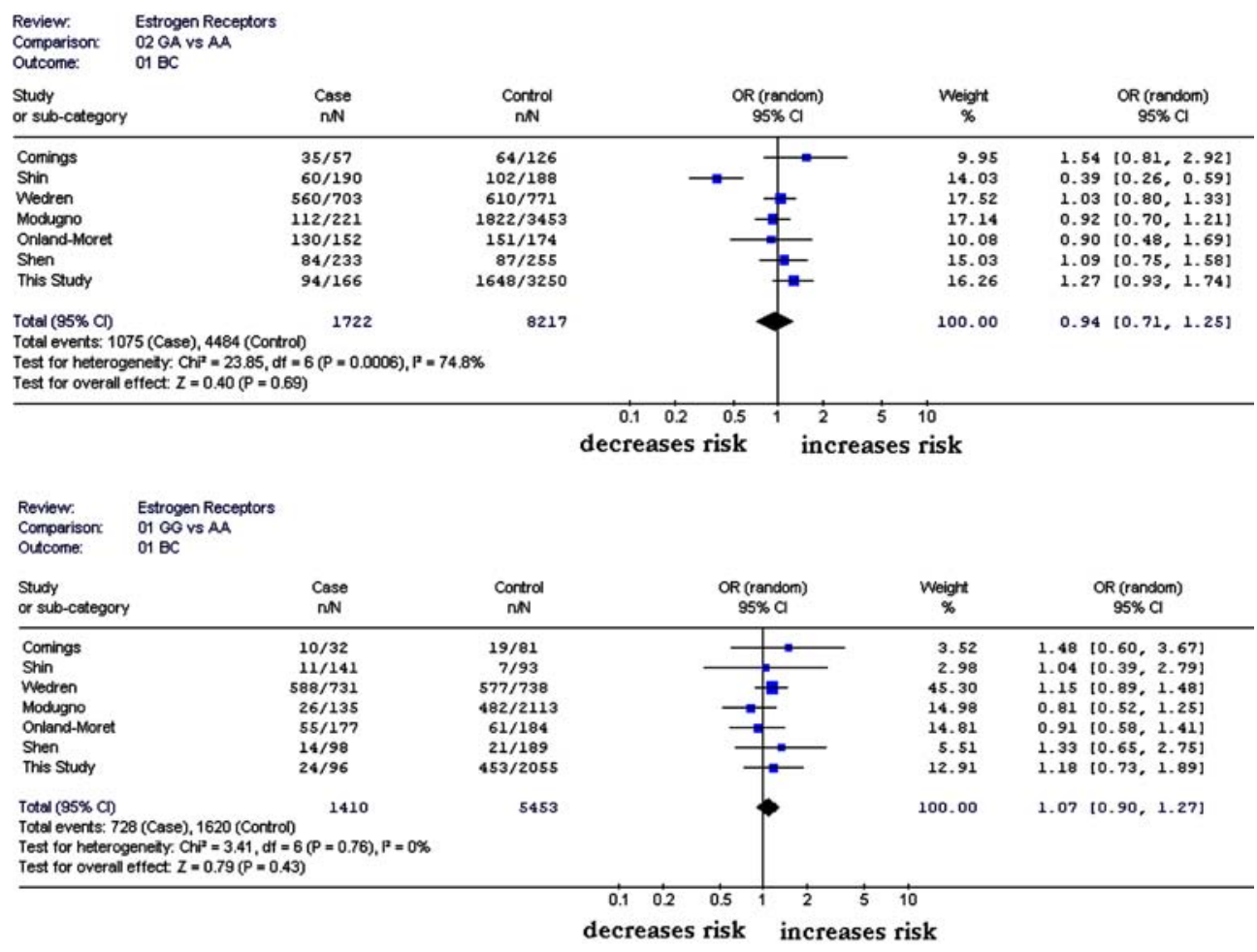

Fig. 2 Meta Analysis ESR1 PvuII polymorphism and breast Review: Estrogen Receptors $\begin{array}{ll}\text { Comparison: } & 04 \mathrm{CT} \text { vs TT } \\ \text { Outcome: } & 01 \mathrm{BC}\end{array}$

Outcone: cancer risk

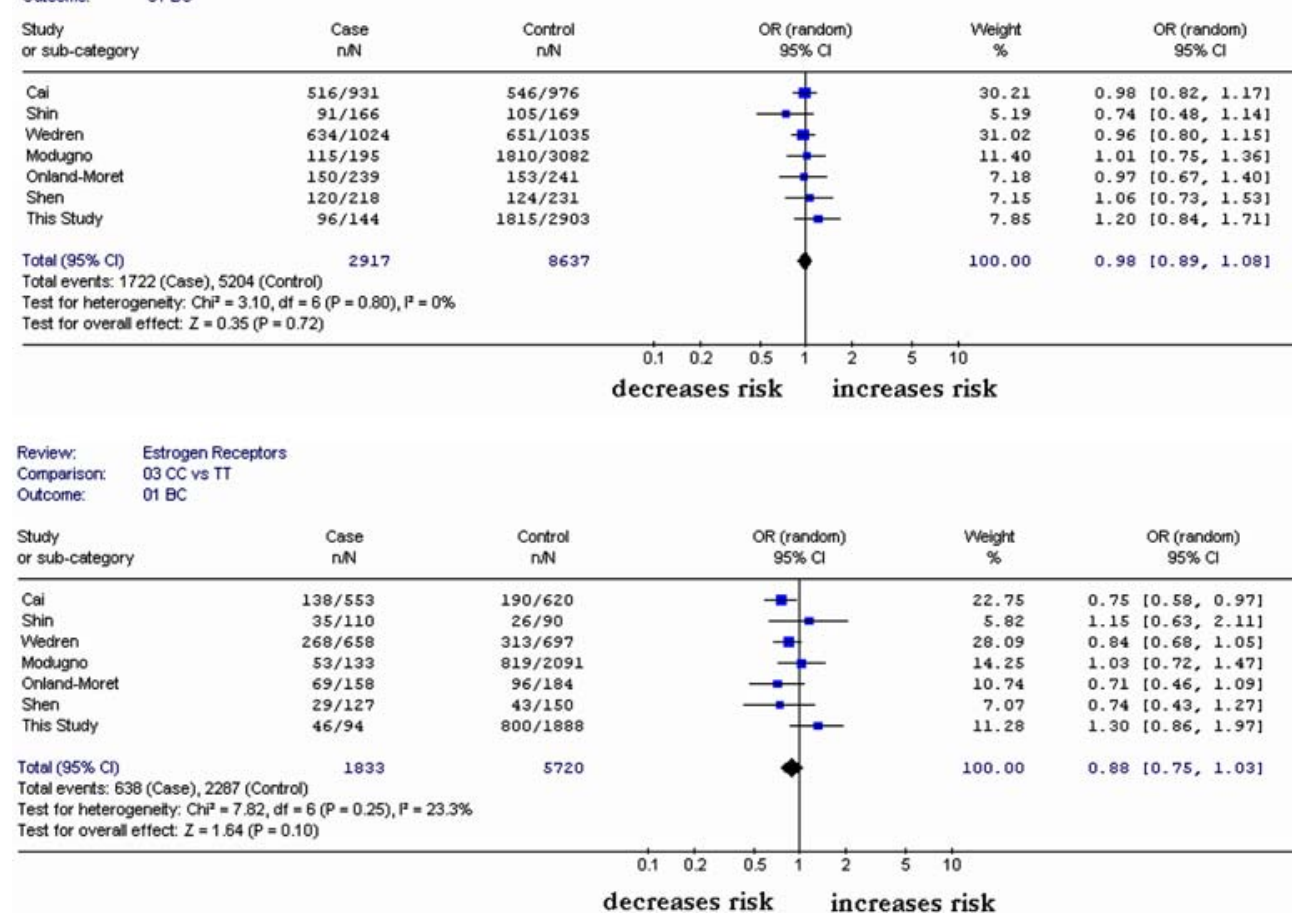

theless, we have sufficient power $(\beta=0.8)$ to detect effects of 1.6 or higher. We further conducted meta-analyses off all studies conducted to date. Our data suggests that these two polymorphisms do not play a role in the susceptibility of breast cancer in elderly Caucasian women.
Acknowledgements A Arias Vasquez is supported by a grant from the Center of Medical Systems Biology, grant \# 297-2003. The Rotterdam Study is supported by the Erasmus Medical Center and Erasmus University Rotterdam, the Netherlands Organization for Scientific Research (NWO), the Netherlands Organization for Health Research and Development (ZonMw), the Research Institute for 
Diseases in the Elderly (RIDE), the Ministry of Education, Culture and Science, the Ministry of Health, Welfare and Sports, the European Commission (DG XII), and the Municipality of Rotterdam.These sponsors had no role in study design, data collection, data interpretation, or the writing of this report. A Arias Vásquez contributed with the design of the study and also participated in the data analyses. CM van Duijn participated in the design and writing of the manuscript. F Rivadeneira, J Witteman, HAP Pols, BHCh Stricker, AG Uitterlinden and A Hofman aided in the data collection and the writing of this manuscript as well.

\section{References}

1. Hulka BS, Moorman PG (2001) Breast cancer: hormones and other risk factors. Maturitas 38(1):103-13; discussion 113-116

2. Lichtenstein P, Holm NV, Verkasalo PK, Iliadou A, Kaprio J, Koskenvuo $\mathrm{M}$ et al (2000) Environmental and heritable factors in the causation of cancer-analyses of cohorts of twins from Sweden, Denmark, and Finland. N Engl J Med 343(2):78-85

3. Feigelson HS, Henderson BE (2000) Future possibilities in the prevention of breast cancer: role of genetic variation in breast cancer prevention. Breast Cancer Res 2(4):277-282

4. Shin A, Kang D, Nishio H, Lee MJ, Park SK, Kim SU et al (2003) Estrogen receptor alpha gene polymorphisms and breast cancer risk. Breast Cancer Res Treat 80(1):127-131

5. Han W, Kang D, Lee KM, Kim HJ, Ahn SJ, Kim SW et al (2003) Full sequencing analysis of estrogen receptor-alpha gene polymorphism and its association with breast cancer risk. Anticancer Res 23(6C):4703-4707

6. Gosden JR, Middleton PG, Rout D (1986) Localization of the human oestrogen receptor gene to chromosome $6 \mathrm{q} 24-\mathrm{q} 27$ by in situ hybridization. Cytogenet Cell Genet 43(3-4):218-220

7. Ponglikitmongkol M, Green S, Chambon P (1988) Genomic organization of the human oestrogen receptor gene. Embo J 7(11):3385-3388

8. Castagnoli A, Maestri I, Bernardi F, Del Senno L (1987) PvuII RFLP inside the human estrogen receptor gene. Nucleic Acids Res 15(2):866

9. Andersen TI, Heimdal KR, Skrede M, Tveit K, Berg K, Borresen AL (1994) Oestrogen receptor (ESR) polymorphisms and breast cancer susceptibility. Hum Genet 94(6):665-670

10. Cai Q, Shu XO, Jin F, Dai Q, Wen W, Cheng JR et al (2003) Genetic polymorphisms in the estrogen receptor alpha gene and risk of breast cancer: results from the Shanghai breast cancer study. Cancer Epidemiol Biomarkers Prev 12(9):853-859
11. Kang HJ, Kim SW, Kim HJ, Ahn SJ, Bae JY, Park SK et al (2002) Polymorphisms in the estrogen receptor-alpha gene and breast cancer risk. Cancer Lett 178(2):175-180

12. Modugno F, Zmuda JM, Potter D, Cai C, Ziv E, Cummings SR et al(2005) Association of estrogen receptor alpha polymorphisms with breast cancer risk in older Caucasian women. Int $\mathrm{J}$ Cancer 116(6):984-991

13. Yaich L, Dupont WD, Cavener DR, Parl FF (1992) Analysis of the PvuII restriction fragment-length polymorphism and exon structure of the estrogen receptor gene in breast cancer and peripheral blood. Cancer Res 52(1):77-83

14. van Meurs JB, Schuit SC, Weel AE, van der Klift M, Bergink AP, Arp PP et al (2003) Association of $5^{\prime}$ estrogen receptor alpha gene polymorphisms with bone mineral density, vertebral bone area and fracture risk. Hum Mol Genet 12(14):1745-1754

15. Schuit SC, van Meurs JB, Bergink AP, van der Klift M, Fang Y, Leusink G et al (2004) Height in pre- and postmenopausal women is influenced by estrogen receptor alpha gene polymorphisms. J Clin Endocrinol Metab 89(1):303-309

16. Hofman A, Grobbee DE, de Jong PT, van den Ouweland FA (1991) Determinants of disease and disability in the elderly: the Rotterdam Elderly Study. Eur J Epidemiol 7(4):403-422

17. Garrow J (1986) Quetelet index as indicator of obesity. Lancet 1(8491): 1219

18. Raymond MRF (1986) Genepop (version 1.2): population genetics software for exact tests and ecumenism. J Heredity $86: 248-249$

19. DerSimonian R, Laird N (1986) Meta-analysis in clinical trials. Control Clin Trials 7(3):177-188

20. Macaskill P, Walter SD, Irwig L (2001) A comparison of methods to detect publication bias in meta-analysis. Stat Med 20(4):641-654

21. Shen Y, Li DK, Wu J, Zhang Z, Gao E (2006) Joint effects of the CYP1A1 MspI, ERalpha PvuII, and ERalpha XbaI polymorphisms on the risk of breast cancer: results from a populationbased case-control study in Shanghai, China. Cancer Epidemiol Biomarkers Prev 15(2):342-347

22. Wedren S, Lovmar L, Humphreys K, Magnusson C, Melhus H, Syvanen AC, et al (2004) Oestrogen receptor alpha gene haplotype and postmenopausal breast cancer risk: a case control study. Breast Cancer Res 6(4):R437-R449

23. Comings DE, Gade-Andavolu R, Cone LA, Muhleman D, MacMurray JP (2003) A multigene test for the risk of sporadic breast carcinoma. Cancer 97(9):2160-2170

24. Onland-Moret NC, van Gils CH, Roest M, Grobbee DE, Peeters $\mathrm{PH}$ (2005) The estrogen receptor alpha gene and breast cancer risk (The Netherlands). Cancer Causes Control 16(10):1195-1202 